\title{
La Doctrina Jurídica en Chile. Un breve estudio acerca del surgimiento de la figura del jurista en Chile y la educación universitaria
}

\author{
Carlos Felipe Amunátegui Perelló*
}

\begin{abstract}
RESUMEN
Este trabajo aborda el desarrollo de los estudios jurídicos en Chile desde un punto de vista histórico, a fin de intentar iluminar los cambios que se han producido en el panorama jurídico nacional durante los últimos años con la emergencia de un nuevo actor en nuestro ambiente jurídico, el académico investigador.
\end{abstract}

Cultura jurídica - educación - investigación - universidad

\section{Legal Scholarship in Chile. Some considerations on the Development of the Jurist in Chile and Legal Education}

\begin{abstract}
This paper gives a brief review of the historical development of legal studies in Chile in order to give some light on the recent changes that the emergence of a new actor in our legal arena have brought, the scholar researcher.
\end{abstract}

Legal cultur - education - research - university

* Licenciado en Ciencias Jurídicas y Sociales de la Pontificia Universidad Católica de Chile. Abogado. Doctor en Derecho, Universidad Pompeu Fabra, España. Profesor de Derecho romano, Pontificia Universidad Católica de Chile. Correo electrónico: camunate@uc.cl. Este artículo es parte del proyecto Fondecyt 1141231 y de Anillos de Investigación Asociativa SOC1111.

Artículo recibido el 16 de febrero de 2015 y aceptado para su publicación el 21 de enero de 2016. 


\section{INTRODUCCIÓN}

$\mathrm{E}$ n los últimos años las aguas del derecho civil en Chile parecen estar más bien tranquilas. No se vislumbra nada tan drástico como una reforma al Código Civil ${ }^{1}$, ni tampoco la legislación miscelánea parece estar afectando en forma profunda al Derecho Privado. Por el contrario, con algunas excepciones de relativa importancia en el Derecho Comercial, su marco jurídico se mantiene estable, mientras que los poderes políticos, en general, se han abstenido de introducir innovaciones radicales. No obstante, bajo esta apariencia tranquila, diversas innovaciones jurídicas han emergido a paso ligero ${ }^{2}$, e incluso algunas reformas que se pretendía introducir por vía legislativa, se han terminado por implementar por la Jurisprudencia de la propia Corte Suprema por consideraciones estrictamente dogmáticas ${ }^{3}$.

Parece sorprendente que un país una vez orgulloso de su tradición positivista ${ }^{4}$ haya decidido acometer la empresa de crear nuevas formas dogmáticas al margen de la intervención legislativa. Hace solo veintidós años, en 1992, cuando yo comenzaba mis estudios de Derecho, el presidente de la Corte Suprema declaraba en su discurso inaugural ${ }^{5}$ :

${ }^{1}$ La última reforma del Código Civil fue bastante anodina. Consistió en modificar las reglas concernientes a la muerte presunta (L.20577 de febrero de 2012). Antes de esto, hubo reformas masivas en filiación, que fueron producto de la Ley $\mathrm{N}^{\circ} 19.585$ de 1998. Estas son bastante antiguas y, de momento, no nos conciernen.

${ }^{2}$ Simplemente a fin de citar algunos desarrollos recientes, apareció la teoría de las inmisiones en el Derecho Civil chileno (vid: Amunátegui Perelló, Carlos Felipe, Derecho Civil y Medioambiente, Thomson Reuters Santiago, 2014; el análisis económico entró al razonamiento de los jueces a propósito de la distribución de riesgos (vid: Aedo Barrena, Cristián, "El concepto normativo de la culpa como criterio de distribución de riesgos. Un análisis jurisprudencial" en Revista Chilena de Derecho 41-2 (2014), pp. 705-728) y la responsabilidad por daño moral apareció en las relaciones contractuales (vid: Rutherford Parentti, Romy Grace, "La reparación del daño moral derivado del incumplimiento contractual: tendencia en la reciente jurisprudencia nacional y española" en Revista Chilena de Derecho 40-2 (2013), pp. 669-689), mientras que la Corte Suprema (no sin vacilaciones), finalmente optó por la doctrina francesa y reguló en la responsabilidad extracontractual la llamada responsabilidad precontractual (vid: San Martín Neira, Lilian C., "Responsabilidad precontractual por ruptura injustificada de negociaciones. Revista Chilena de Derecho, 40-1 (2013), 317-324).

${ }^{3}$ En un caso muy controvertido, recientemente la Corte Suprema prohibió la contratación de rompe huelgas. Este asunto estaba en la agenda legislativa de gobierno, pero aún no se ha aprobado. La Corte Suprema decidió, el 4 de diciembre de 2014, que la interpretación de la disposición que permitía la contratación de tal personal de reemplazo (art. 381 del Código del Trabajo) no cumplía las obligaciones internacionales de Chile de conformidad a las convenciones 87 y 98 de la OIT, debiendo interpretarse el Código del Trabajo de acuerdo a dichas convenciones y de manera armónica con sus responsabilidades internacionales.

${ }^{4}$ Vid: Barahona González, Jorge, "La cultura jurídica chilena: apuntes históricos, tendencias y desafíos", en Revista de Derecho (Valparaíso) 35-2 (2010), pp. 427-448; González Morales, Felipe, "Cultura Judicial y Enseñanza del Derecho en Chile: una aproximación” en Colección de Informes de Investigación 14-5 (2003), p. 6 y Bravo Lira, Bernardino, "Estudios de Derecho y Cultura de abogados en Chile 1758-1998: tras la huella ius commune, codificación y descodificación en el nuevo mundo", en REHJ 20 (1998), pp. 85-106.

${ }^{5}$ Diario Oficial de Chile, 15 de marzo de 1992. El discurso fue dado por el presidente de la Corte Suprema el 11 de marzo de 1992. Véanse comentarios al respecto en: Bravo Lira, Bernardino, "Estudios de Derecho y Cultura de abogados en Chile 1758-1998: tras la huella ius commune, codificación y descodificación 
"la ley la dicta el poder político -Poder Legislativo y Poder Ejecutivo- y ellos dicen lo que es justo, sin que sea permitido al juez discutir o dudar de la justicia que la ley encierra".

Esta declaración, que parece sacada de las pesadillas de la École de l'Exégèse era, en efecto, el mismísimo estado del arte de la ciencia jurídica chilena de la transición. Hace veinte años, Derecho Civil era una asignatura soñolienta, donde la mayor parte de las obras de referencia provenían de la década de los treinta, mientras que las cortes aplicaban un razonamiento simplista sacado, muchas veces sin saberlo, de la añejísima escuela pandectista. Las perspectivas históricas y comparadas estaban simplemente fuera del alcance de los alumnos, mientras que los profesores las omitían. Sin embargo, en solo veinte años este poco promisorio panorama ha cambiado radicalmente de una manera imprevista. El Derecho Privado se ha convertido en una arena vibrante gracias a la emergencia de un nuevo elemento en la tradición jurídica nacional, la investigación jurídica.

Aunque la importancia del jurista en las tradiciones continentales no puede ser sobreestimado ${ }^{6}$, uno de los mayores problemas de la tradición jurídica privada en Chile era la total ausencia de investigación. En general, se realizaba poca investigación en las universidades, porque los profesores de Derecho eran, usualmente, abogados en ejercicio que podían exhibir pocas credenciales académicas. Las publicaciones eran, normalmente, manuales de corto vuelo que intentaban simplificar trabajos previos -generalmente de juristas franceses del cambio de comienzos del siglo veinte- para hacerlos accesibles para los estudiantes.

A fin de poner algunas cifras, podemos citar el interesante trabajo de Joel González ${ }^{7}$ publicado en 2005. Este es un índice de toda la literatura jurídica de Derecho Civil publicada desde la Independencia hasta el año de su aparición. Incluía más de mil doscientos trabajos entre libros y artículos de revista. En su segunda edición, que está a punto de aparecer, el número de entradas bibliográficas se ha duplicado. Es decir, en los últimos diez años se ha producido más literatura jurídica que en los precedentes doscientos años. Estos números son elocuentes y muestran un auge rápido de la doctrina jurídica privada. Esto es el resultado de los muy recientes avances en la educación y cultura jurídicas nacionales que este trabajo pretende resumir. Para hacerlo, tomaremos una perspectiva histórica, analizando el estado de la educación jurídica en Chile durante la Colonia, los siglos diecinueve y veinte, para luego exponer su desarrollo actual.

en el nuevo mundo", en REHJ 20 (1998), pp. 85-106 y Barahona González, Jorge, "La cultura jurídica chilena: apuntes históricos, tendencias y desafíos”, en Revista de Derecho (Valparaíso) 35-2 (2010), pp. $427-448$

${ }^{6}$ En la materia, la opinión de Peter Stein sigue siendo un clásico. Pone al jurista en el corazón de la diferencia entre los sistemas de Derecho Civil y Common law. Vid: Stein, Peter, "Judge and Jurist in the Civil Law: A Historical Interpretation” en Louisiana Law Review 46-2 (1985), pp. 241-257.

${ }^{7}$ González, Joel, Índice Chileno de Derecho Privado. 1.200 Artículos de Derecho Civil y Derecho Comercial, Editorial Jurídica, Santiago, 2005. 


\section{LOS JURISTAS Y LA EDUCACIÓN JURÍDICA EN EL CHILE COLONIAL}

La Historia de los juristas en la América española comienza de una manera un tanto extraña. Durante el debut de la Conquista se prohibió a los abogados cruzar el Océano y entrar a las posesiones españolas de América ${ }^{8}$. En 1509 una Real Cédula promulgada por Carlos V prohibía a los abogados viajar a América, salvo que tuviesen una licencia especial del rey ${ }^{9}$. El argumento dado fue que los abogados promueven los pleitos y el descontento social $^{10}$. En cualquier caso, en 1526 , la prohibición fue reemplazada por la necesidad de una licencia especial de la Corona, a raíz de una petición del Cabildo de la Ciudad de México.

Durante la Conquista de Chile, las primeras capitulaciones dadas a los conquistadores para ocupar el territorio que eventualmente se convertiría en Chile ${ }^{11}$ incluían esta prohibición. Sin embargo, unas pocas décadas más tarde, en 1560, la disposición, que ya se había relajado, fue reemplazada por la necesidad general de una licencia para cualquiera que quisiese migrar a América ${ }^{12}$. Esto incluía, claro está, a los abogados, aunque ya no pesaba sobre ellos una prohibición específica. No obstante, mucho antes de entonces, varios abogados habían entrado a las colonias españolas. El primero en llegar a Chile lo hizo, de hecho, en 1549.

Si los niveles de alfabetismo en todo el Imperio Español eran malos, en el Chile del siglo dieciséis estos eran decididamente catastróficos. Algunos de los fundadores de Santiago no eran capaces de escribir ni sus nombres y la mayor parte lo hacía con dificultades $^{13}$. Los únicos lugares donde sus hijos podían obtener alguna clase de educación eran los colegios privados fundados por algunas órdenes religiosas. Debido a la ausencia

${ }^{8}$ González Echeñique, Javier, Los Estudios Jurídicos y la Abogacía en el Reino de Chile, Tesis para el Grado de Licenciado, Universidad Católica de Chile, Facultad de Ciencias Jurídicas, Políticas y Sociales, 1954 , pp. 23-25.

${ }^{9}$ El documento fue publicado en la Colección de Documentos Inéditos Relativos al Descubrimiento, Conquista y Organización de las Antiguas Posesiones Españolas de Ultramar, Real Academia de la Historia, Madrid, 1890, t.5, pp. 187-193

${ }^{10}$ La parte relevante dice, en castellano arcaico:

"ansi mismo porque yo he seydo ynformado que a cabsa de aver pasado alas dichas yndias algunos letrados abogados han subcedido en ellas muchos pleitos e difierencias yo vos mando que de aqui adelante no dexeys ny consyntays pasar a las dichas yndias ningund letrado abogado syn nuestra licencia e especial mandado que sy necesario es por esta presente cédula lo vedamos e proyvimos".

${ }^{11}$ Estas son las capitulaciones realizadas para Simón de Alcazaba en 1526, Diego de Almagro, Pedro de Mendoza y de nuevo Simón de Alcazaba en 1534, Francisco de Camargo en 1536 y Sancho de la Hoz en 1539. Vid: González Echeñique, Javier, Los Estudios Jurídicos y la Abogacía en el Reino de Chile, Tesis para el Grado de Licenciado, Universidad Católica de Chile, Facultad de Ciencias Jurídicas, Políticas y Sociales, 1954, p. 26.

${ }^{12}$ Vid: 1.1 y ss., tit. 26, b. IX de la Recopilación de Leyes de Indias, Bartholome Ulloa, Madrid, 1774 , p. 1 y ss.

13 Medina, José Toribio, La instrucción pública en Chile, imprenta Elzeviriana, Santiago, 1905, p. 13. Una visión más optimista la da Sol Serrano, para quien el hecho que solo 90 de los 150 españoles que vinieron con Valdivia pudiesen firmar parece estar muy por sobre la media de la metrópolis. Vid: Serrano, Sol, Ponce de León, Macarena y Rengifo, Francisca, Historia de la Educación en Chile, (1810-2010), Taurus, Santiago, 2012, t.I, p. 17 
de cualquier tipo de institución que pudiese dar algún tipo de educación superior en todo el Cono Sur, estas órdenes religiosas, amparadas por las regulaciones canónicas ${ }^{14}$, establecieron dos universidades pontificias en Santiago. Sin embargo, ninguna de estas instituciones enseñaba Derecho, y los descendientes de los conquistadores debían viajar a Lima a fin estudiar Derecho a la Real Universidad de San Marcos, algo muy oneroso, de acuerdo con los testimonios de la época ${ }^{15}$. De hecho, esta fue una de las principales razones aducidas por el Cabildo de Santiago al solicitar el establecimiento de una universidad Real en Santiago en $1713^{16}$. Según el cabildo, había solo unos pocos abogados en Chile y era casi imposible para las familias chilenas enviar a sus hijos a estudiar a Lima.

Luego de una lucha de veinticinco años -y de la completa asunción de todos los gastos que la universidad generase por parte del Cabildo de Santiago-, el 28 de julio de 1738 el rey aceptó conceder una universidad real para Chile, esta fue la Real Universidad de San Felipe.

Aunque hay muchas razones para alabar a la Corona española por la calidad de sus universidades en América, la Real Universidad de San Felipe no debe ser considerada como un logro de su política. Fue, probablemente, una de las universidades más pobres de todo el Imperio Español, como también una de las más corruptas. El presupuesto total (cinco mil pesos) era menos que el salario del rector de la Universidad de Salamanca en ese entonces (ocho mil pesos). En cualquier caso, este presupuesto modesto fue administrado con irresponsabilidad ${ }^{17}$, por lo que la Universidad regularmente no estaba en

${ }^{14}$ Estas regulaciones establecían que en los territorios que estuviesen a lo menos a 500 millas de una Universidad Real, las órdenes religiosas podrían fundar una (Recopilación de Leyes de Indias, 1.2, tit.22, lib. 1). De acuerdo a estas disposiciones, ambos, los Dominicos (1621) y los Jesuitas (1617) establecieron sus propias universidades privadas. Vid: Medina, José Toribio, La instrucción pública en Chile, imprenta Elzeviriana, Santiago, 1905, pp. 168-169; González Echeñique, Javier, Los Estudios Jurídicos y la Abogacía en el Reino de Chile, Tesis para el Grado de Licenciado, Universidad Católica de Chile, Facultad de Ciencias Jurídicas, Políticas y Sociales, 1954, pp. 82-89; Bravo Lira, Bernardino, "Estudios de Derecho y Cultura de abogados en Chile 1758-1998: tras la huella ius commune, codificación y descodificación en el nuevo mundo", en REHJ 20 (1998), pp. 85-106.

${ }^{15}$ Hubo incluso becas, pero estas parecen haber sido insuficientes para las necesidades del Reino. Vid: González Echeñique, Javier, Los Estudios Jurídicos y la Abogacía en el Reino de Chile, Tesis para el grado de Licenciado, Universidad Católica de Chile, Facultad de Ciencias Jurídicas, Políticas y Sociales, 1954, p. 60.

${ }^{16}$ El texto de la petición se publicó por primera vez en Medina, José Toribio, La instrucción pública en Chile, imprenta Elzeviriana, Santiago, 1905, p. 381. Al respecto dice: "Y que lo persuadió al dicho señor alcalde el hacer esta propuesta el considerar que los vecinos de esta ciudad, que con tanta liberalidad contribuyen á la dicha balanza, escaseándolo aún de lo preciso de sus familias, se hallen atrasados y sumamente pobres, y que por falta de medios dejan de remitir sus hijos á la Real Universidad de San Marcos de Lima, donde, después de los peligros y contingencias de una dilatada embarcación, son los gastos excesivos y que no pueden sufrir sus caudales... y que bien les constaba á los dichos señores cuan falto se hallaba el reino de personas peritas en la Facultad de Cánones y Leyes para cualquier duda ó consejo que se pudiese tomar, y que los negocios eran muchos y muy graves, y que hoy sólo se hallaban tres abogados seglares y dos eclesiásticos, y que no discurría que por ahora hubiese vecino de este reino que tuviese ánimo de remitir un hijo suyo á estudiar á la dicha Universidad de los Reyes, por los crecidos gastos, que cada día van en aumento"

${ }^{17}$ La Universidad solía gastar una buena parte de su presupuesto en ceremonias muy onerosas y en fiestas, por ejemplo, para la recepción de un nuevo gobernador de Chile. Vid: Fuenzalida Grandón, Alejandro, Historia del desarrollo intelectual en Chile, Imprenta Universitaria, Santiago, 1903, pp. 24-34. 
condiciones de pagar a sus profesores ${ }^{18}$. A fin de resolver sus problemas económicos, la Universidad optó por vender grados y, en especial, títulos doctorales bajo el nombre de indulgencias. Aunque este procedimiento no fue único de la Universidad de San Felipe, porque también otras universidades españolas lo utilizaron, en ningún otro lugar alcanzó el grado de sistematicidad que tuvo en Chile. Comenzando por su primer rector, Tomás de Azúa, que se autoconfirió el título de doctor utrusque iuris inmediatamente después de ser nombrado ${ }^{19}$ y ocho años antes que se diese clase alguna en la Universidad (1748), muchos otros miembros de la aristocracia nacional pagaron sabrosas sumas de dinero por el privilegio de ser llamados doctor.

La construcción del edificio de la Universidad fue financiada con la venta de $\operatorname{grados}^{20}$. Esta práctica se hizo tan desafortunadamente conspicua que en 1758, poco después que la Universidad finalmente se abriese e impartiese sus primeras clases, su consejo decidió nunca más otorgar el título de doctor a quien no hubiese cursado los estudios requeridos ${ }^{21}$. Por supuesto, la Universidad no fue capaz de cumplir su decisión y en poco tiempo la Universidad había vuelto al negocio de la venta de títulos. En 1785 el estado económicamente ruinoso de la Universidad impulsó a sus autoridades a llevar las cosas un paso más allá. La Universidad abrió una feria de grados donde se subastaron veinticinco títulos de doctor. Este proceso fue repetido en varias oportunidades durante sus noventa años de historia. Algunos de estos títulos eran incluso transferibles, por lo que el afortunado doctor que lo adquiriese podía, a su vez, negociarlo y venderlo.

Como sea, el modelo seguido en la creación de la Universidad fue la Real Universidad de San Marcos de Lima, cuyas constituciones adoptó la Real Universidad de San Felipe ${ }^{22}$. Derecho era por lejos la carrera más importante de la Universidad. De las diez cátedras que tenía, cuatro eran para Derecho ${ }^{23}$. Estas eran: Institutas, donde se enseñaban los rudimentos del Derecho Romano por medio de las Instituciones de Justiniano, tal vez comentadas por Vinnius; Prima de Leyes, donde se enseñaban casos del Digestum

${ }^{18}$ Fuenzalida, uno de los más importantes historiadores que trató la institución, dice que la excusa más frecuente dada por los profesores para no dar sus clases fue la impuntualidad en el pago de sus remuneraciones. Vid: Fuenzalida Grandón, Alejandro, Historia del desarrollo intelectual en Chile, Imprenta Universitaria, Santiago, 1903, p. 34.

19 Amunátegui, Miguel Luis, "La Universidad de San Felipe”, en Anales de la Universidad de Chile (1874), p. 15 .

${ }^{20}$ Miguel Luis Amunátegui señala que los materiales fueron comprados a los monjes mercedarios a cambio de tres títulos de doctor en teología. Vid: Amunátegui, Miguel Luis, "La Universidad de San Felipe", en Anales de la Universidad de Chile (1874), p. 16

${ }^{21}$ Amunátegui, Miguel Luis, "La Universidad de San Felipe", en Anales de la Universidad de Chile (1874), p. 23.

${ }^{22}$ Bravo Lira, Bernardino, "Estudios de Derecho y Cultura de abogados en Chile 1758-1998: tras la huella ius commune, codificación y descodificación en el nuevo mundo”, en REHJ 20 (1998), pp. 85-106.

${ }^{23}$ Véase la Real Cédula que creó la Universidad en Amunátegui, Miguel Luis, "La Universidad de San Felipe", en Anales de la Universidad de Chile (1874), p. 5. 
infortiatum $^{24}$; Prima de Cánones, para las Decretales de Gregorio IX y Decreto ${ }^{25}$, para el Decreto de Graciano ${ }^{26}$.

En todo caso, ha de señalarse que tanto los alumnos como los profesores sistemáticamente faltaban a clases y que la Universidad nunca estuvo en condiciones de imponer una programación estricta. Luego de solo dos años de su inauguración formal, el rector José Valeriano Ahumada decidió revisar los contenidos de los cuadernos de los alumnos. La mayor parte estaban simplemente en blanco y sin apuntes ${ }^{27}$. De hecho, probablemente muy pocas clases se dieron alguna vez en esa casa de estudios. Una descripción de sus actividades académicas realizada en $1795^{28}$ señala que todo el año académico se reducía a cuatro meses donde se realizaba una clase diaria de una hora y media.

A estos mediocres antecedentes debemos agregar que la Universidad no tenía biblioteca y que solo pudo hacerse con una cuando los jesuitas fueron expulsados de Chile en 1767, logrando obtener la transferencia de sus libros confiscados en $1771^{29}$. Aunque los jesuitas no enseñaban Derecho, su biblioteca estaba centrada en la filosofía y la teología. En estas condiciones, con muy pocas clases, sin apuntes ni biblioteca, parece más bien difícil imaginar qué clase de formación jurídica pudiese darse en ella. La Universidad estaba básicamente centrada en tomar exámenes y los estudiantes solían estudiar los cursos teóricamente dictados en ella de manera privada, con profesores particulares o en el Colegio de San Carlos, que fue establecido en 1769 luego de la expulsión de los jesuitas $^{30}$. En 1813, en los comienzos del proceso de Independencia, este fue el juicio crítico que mereció la Universidad por parte del Congreso: "La Universidad, considerando su constitución, es más una casa de exámenes que un establecimiento educacional” 31.

No resulta sorprendente que no se conozca obra jurídica alguna del Chile colonial. Algunas fueron escritas en Chile por funcionarios públicos que casualmente estaban

${ }^{24}$ Desde el libro 23 al 38 del Digesto de Justiniano.

${ }^{25}$ Estas cátedras eran nombradas por el Gobernador de Chile. Se llenaron por primera vez en 1755 , un año antes de la apertura de la Universidad. Vid: Fuenzalida Grandón, Alejandro, Historia del desarrollo intelectual en Chile, Imprenta Universitaria, Santiago, 1903, p. 5.

26 Vid: Guzmán Brito, Alejandro, "La enseñanza de Derecho en Chile. Historia y perspectivas", en Anales del Instituto de Chile 25 (2005-6), p. 315 y Barrientos Grandón, Javier, "El derecho común y el Derecho indiano en el Reino de Chile” pp. 133-159.

${ }^{27}$ Vid: Medina, José Toribio, Historia de la Real Universidad de San Felipe de Santiago de Chile, Universo, Santiago, 1928, t.I, pp. 66-67

${ }^{28}$ La descripción fue dada por Francisco Javier Errázuriz en 1795. Fue publicada en Fuenzalida Grandón, Alejandro, Historia del desarrollo intelectual en Chile, Imprenta Universitaria, Santiago, 1903, p. 102.

${ }^{29}$ Vid: Fuenzalida Grandón, Alejandro, Historia del desarrollo intelectual en Chile, Imprenta Universitaria, Santiago, 1903, p. 54.

${ }^{30}$ González Echeñique, Javier, Los Estudios Jurídicos y la Abogacía en el Reino de Chile, Tesis para el Grado de Licenciado, Universidad Católica de Chile, Facultad de Ciencias Jurídicas, Políticas y Sociales, 1954 , p. 163.

31 Sesiones de los Cuerpos Lejislativos de la República de Chile. 1811 a 1845, Santiago, Cervantes, 1887 , t. 1, p. 297. 
en el reino durante la Colonia ${ }^{32}$, mas ninguna fue publicada en Chile, ya que no hubo imprenta hasta 1812, época en que comienza el proceso de Independencia.

\section{LA UNIVERSIDAD DE BELLO}

Durante el proceso de Independencia, la educación pública fue uno de los muchos objetivos que se fijó la revolución. De hecho, en 1811 se presentó ante el recién establecido Congreso un nuevo plan para reemplazar completamente el modelo educacional colonial $^{33}$. El plan consistía en la fusión de todos los establecimientos educacionales de Chile en un solo instituto que asumiría todas las ramas de la educación superior. Esta institución, el Instituto Nacional, impartiría clases y tomaría exámenes, dejando a la vieja Universidad Real confinada a ser una mera academia con la misión de otorgar grados. En 1813, en medio de la guerra de Independencia, se fundó el Instituto Nacional por orden de la Junta de Gobierno, el Senado y el Cabildo de Santiago ${ }^{34}$.

Aunque el modelo educacional tenía la apariencia de un seminario, porque los estudiantes debían rezar diariamente y realizar todo tipo de ejercicios espirituales, la fundación del Instituto Nacional significó una reorganización masiva de los estudios de Derecho. El viejo vicio de vender los títulos universitarios fue suprimido y el otorgamiento de cualquier tipo de grado sin antes rendir los exámenes correspondientes fue prohibido $^{35}$. De hecho, el título de doctor mismo cayó en el olvido, probablemente por sus connotaciones monárquicas y la dudosa tradición que lo respaldaba ${ }^{36}$.

La vieja Universidad de San Felipe, de conformidad con la tradición universitaria medieval, no enseñaba ninguna forma de Derecho Positivo, sino que centraba su currículo en el Derecho Romano y Canónico. El recientemente fundado Instituto hacía, por su parte, exactamente lo contrario. Suprimió Derecho Romano, reemplazándolo por el Derecho Positivo. Tenía dos cátedras, una para Derecho Natural y Derecho de Gentes, donde también se enseñaba economía Política, y otra para Derecho Positivo y Canónico.

${ }^{32}$ Sabemos de ocho trabajos, el primero de ellos escrito en 1633 y el último publicado después de la Independencia. Vid: González Echeñique, Javier, Los Estudios Jurídicos y la Abogacía en el Reino de Chile, Tesis para el Grado de Licenciado, Universidad Católica de Chile, Facultad de Ciencias Jurídicas, Políticas y Sociales, 1954, p. 189.

${ }^{33}$ Vid: Sesiones de los Cuerpos Lejislativos de la República de Chile. 1811 a 1845, Santiago, Cervantes, 1887, t.1, pp. 173-178.

${ }^{34}$ Vid: Sesiones de los Cuerpos Lejislativos de la República de Chile. 1811 a 1845, Santiago, Cervantes, 1887, t.1, pp. 289-322.

35 Vid: Amunátegui y Solar, Domingo, Los primeros años del Instituto Nacional (1813-1835), Impr. Cervantes, Santiago, 1889, p. 153.

${ }^{36}$ El título no fue formalmente abolido. De hecho, O’Higgins promulgó un decreto restringiendo el ejercicio de la abogacía a aquellos que tuviesen un título de doctor en 1821, pero su decreto nunca fue puesto en práctica. En 1832 el grado de doctor, simplemente, no estaba contemplado en la Educación Superior y estuvo ausente de esta hasta el siglo XXI. Vid: Guzmán Brito, Alejandro, "La enseñanza de Derecho en Chile. Historia y perspectivas”, en Anales del Instituto de Chile 25 (2005-6), p. 289. 
Una de las innovaciones más importantes fue el uso de textos impresos para las clases ${ }^{37}$. En Chile, durante la administración colonial no había prensa y la primera fue importada recién en 1812. En cuanto a la adquisición de textos importados, esta era difícil debido a las complejidades de la administración colonial. En fin, durante la Colonia, la falta de libros hizo que la enseñanza del Derecho dependiese de la oralidad y la tradición. En el recientemente fundado Instituto, los libros se convirtieron, finalmente, en el corazón de los estudios jurídicos. No obstante, las vicisitudes de la guerra de Independencia forzaron el cierre del Instituto Nacional luego de la derrota de Rancagua ${ }^{38}$, aunque cuando el país estuvo finalmente bajo el control de los independentistas el Instituto fue reabierto en 1819, siguiendo muy de cerca el modelo original.

El Instituto Nacional dejó al sistema de educación chileno con dos particularidades muy curiosas. En primer término, la Universidad fue mantenida como una suerte de Academia de Ciencias, que impartía los grados de educación superior, pero que carecía de un control directo sobre la educación en sí. En segundo término, se mantuvo la posibilidad de que cualquiera pudiese estudiar privadamente las materias y obtuviese los grados mediante la toma de los exámenes correspondientes en el Instituto. Estas dos características se mantendrán como centrales en el sistema de educación chileno durante todo el período en estudio.

La baja calidad de la Universidad de San Felipe dejó un estigma en todo el sistema universitario. Durante la República temprana, las atribuciones de la Universidad estaban restringidas a un mínimo. De hecho, cuando el rector de la Universidad de San Felipe reclamó para la Universidad la facultad de tomar exámenes independientemente del Instituto, la Universidad simplemente fue cerrada ${ }^{39}$. La Universidad de Chile, que fue establecida para reemplazarla, era más bien una academia que una universidad ${ }^{40}$. No obstante, tenía más control sobre la educación impartida en el Instituto que la Universidad de San Felipe, porque sus profesores podían integrar las comisiones que tomaban los exámenes y ya que era la Universidad la que establecía los currículos educacionales que conducían a la obtención de grados universitarios. En cierto modo, el Instituto enseñaba lo que la Universidad aprobaba. De cualquier forma, la Universidad

${ }^{37}$ El Derecho Natural se enseñaba usando los Elementa iuris naturae et gentium, de Johann Gottlieb Heineccius, Economía Política mediante el clásico de Adam Smith, Wealth of Nations, y del Catéchisme d'economie politique de Jean-Baptise Say. En Derecho positivo, que no era otra cosa que Derecho castellano, las Instituciones del Derecho de Castilla de Ignacio Jordán de Asso y Miguel de Manuel fueron el texto preferido. Derecho canónico fue enseñado con la ayuda de las Institutionum canonicarum libri quatuor de Giovanni Devoti. Vid: Guzmán Brito, Alejandro, "La enseñanza de Derecho en Chile. Historia y perspectivas", en Anales del Instituto de Chile 25 (2005-6), p. 316.

${ }^{38}$ Los profesores de la Universidad de San Felipe e incluso algunos de los estudiantes del Instituto presionaron a Mariano Osorio para que reestableciese el viejo modelo educacional. Vid: Amunátegui y Solar, Domingo, Los primeros años del Instituto Nacional (1813-1835), Impr. Cervantes, Santiago, 1889, p. 183.

${ }^{39}$ Este fue el famoso Decreto Egaña que también creó la Universidad de Chile. Acerca de sus detalles, vid: Amunátegui y Solar, Domingo, Los primeros años del Instituto Nacional (1813-1835), Impr. Cervantes, Santiago, 1889, p. 475.

${ }^{40}$ Baeza Marambio, Mario, Esquema y notas para una Historia de la Facultad de Ciencias Jurídicas y Sociales de la Universidad de Chile, Santiago, 1944, p. 100. 
solo obtuvo supervisión directa sobre la educación superior impartida en el Instituto en $1852^{41}$, cuando se creó la Sección Universitaria del Instituto como una rama separada. Esta sección dependía del rector de la Universidad por medio de un delegado universitario. Esta sección fue formalmente incorporada a la estructura universitaria en 1879, cuando la Ley de Instrucción Secundaria y Superior confirió atribuciones educacionales a la Universidad de Chile. Desde este año en adelante, la Universidad de Chile comenzó a enseñar Derecho formalmente.

Respecto de la posibilidad de estudiar en academias privadas, esta posibilidad se dejó vigente con la fundación del Instituto Nacional. De hecho, en 1832 el gobierno decretó explícitamente que los estudiantes de cualquier institución privada podían rendir sus exámenes en el Instituto Nacional ${ }^{42}$. La fundación de la Universidad de Chile (inaugurada formalmente en 1843), no introdujo cambios en dicha situación y la regulación de la Universidad prescribía específicamente en su artículo 15 que esta debía supervigilar los exámenes que se rindiesen en instituciones privadas.

En Santiago, a comienzos de 1830 había al menos dos academias privadas que enseñaban Derecho ${ }^{43}$ : el Liceo de Chile, organizado por el inmigrante español José Joaquín Mora, y el Colegio de Santiago, donde Andrés Bello enseñaba y que eventualmente llegó a presidir. Estas dos instituciones resultaron fundamentales para la reestructuración de la enseñanza del Derecho durante el siglo XIX. Aunque su existencia fue efímera ${ }^{44}$, el Derecho Romano fue reintroducido en los estudios jurídicos mediante ellas. También el Derecho Internacional fue actualizado en su seno. De hecho, sus programas fueron en parte seguidos en la reforma curricular del Instituto Nacional en 1832. Obviamente, debido a la presencia de Andrés Bello en una de estas instituciones, la influencia del Colegio de Santiago fue mayor.

Por influencia de Bello, el Instituto reformó su programa educacional en $1832^{45}$. Este nuevo currículo no solo restableció el Derecho Romano como un curso fundamental

${ }^{41}$ Baeza Marambio, Mario, Esquema y notas para una Historia de la Facultad de Ciencias Jurídicas y Sociales de la Universidad de Chile, Santiago, 1944, p. 102.

42 Boletín de las Leyes y de las Órdenes y Decretos del gobierno de Chile, t. 2, Valparaíso, El Mercurio, 1846, p. 93.

43 Para ese entonces había diez instituciones privadas que impartían educación superior en Santiago. En todo caso, solo dos de estas instituciones enseñaban Derecho. El número de estudiantes que tenían era significativamente inferior que el Instituto Nacional. El Liceo tenía 12 estudiantes de Derecho, mientras que el Colegio solo tenía 8. El Instituto, por su parte, tenía 66 estudiantes de Derecho. Vid: Amunátegui y Solar, Domingo, Los primeros años del Instituto Nacional (1813-1835), Impr. Cervantes, Santiago, 1889, p. 443.

${ }^{44}$ El Liceo fue cerrado luego de la victoria conservadora en Lircay. El Colegio de Santiago también desapareció, cuando la mayor parte de sus autoridades tomaron el control del Instituto Nacional en los primeros años de la década del treinta del siglo XIX.

${ }^{45}$ Para conocer más detalles sobre el programa, véase: Amunátegui y Solar, Domingo, Los primeros años del Instituto Nacional (1813-1835), Impr. Cervantes, Santiago, 1889, p. 521; Baeza Marambio, Mario, Esquema y notas para una Historia de la Facultad de Ciencias Jurídicas y Sociales de la Universidad de Chile, Santiago, 1944, p. 111; Hanisch Espíndola, Hugo, Andrés Bello y su obra en Derecho Romano, Consejo de Rectores de las Universidades Chilenas, Santiago, 1983, p. 28; Guzmán Brito, Alejandro, "La enseñanza de Derecho en Chile. Historia y perspectivas”, en Anales del Instituto de Chile 25 (2005-6), p. 318. 
en la formación de los abogados, sino que también incluyó nuevas materias, como Legislación Universal, un curso basado en la visión que Bello tenía de las ideas de Bentham ${ }^{46}$, y Derecho Internacional, que también era enseñado según el manual de Bello sobre la materia ${ }^{47}$. En pocas palabras, de los cinco años que comprendía el programa de Derecho, tres de ellos eran estudiados exclusivamente con obras escritas por Bello, y cuando la codificación se completó, el cuarto año también se dedicó al estudio de otra obra de Bello ${ }^{48}$.

El plan de 1832 sufrió diversas modificaciones durante el siglo XIX, especialmente a fin de suprimir Legislación Universal ${ }^{49}$-considerada una asignatura demasiado revolucionaria por el obispo de Santiago, el antiguo realista Juan Francisco Meneses- e incluir Derecho Procesal (1853), como también otras materias que fueron codificadas durante el curso del siglo (1859, 1863, 1866, 1872, 1887).

En todo caso, a fines del siglo XIX dos grandes reformas cambiaron fundamentalmente el carácter de los estudios jurídicos. La primera fue la relajación del control ejercido por la Universidad de Chile sobre las instituciones que impartiesen educación superior. En 1872 se promulgó una ley que permitía a cualquier institución privada tomar válidamente exámenes con independencia de la evaluación externa de la Universidad de Chile. En la práctica, esto significó que los estudios jurídicos podían desarrollarse en cualquier institución privada al margen del control estatal. Esta ley permitió la creación de la Universidad Católica de Chile (1888) y de la Universidad Católica de Valparaíso (1888, a partir de un curso de Derecho impartido en los Sagrados Corazones). En el mismo año se permitió a los estudiantes del Instituto dar sus exámenes en cualquier orden que ellos deseasen ${ }^{50}$. En la práctica, esto significó que los programas perdieron buena parte de su sentido y que los alumnos podían estudiar las materias en el orden que deseasen.

${ }^{46}$ Estaba basado en el Traité de Législation Civile et Pénale de Bentham, el que se editó en francés por primera vez (antes que en inglés) por Étienne Dumont en Paris y fue muy influyente en Latinoamérica durante la primera mitad del siglo XIX. Conocemos los contenidos del curso de Bello por los apuntes manuscritos tomados por su alumno Ramón Briseño Calderón. De acuerdo con Domingo Amunátegui, el curso fue enseñado siguiendo las notas de Bello en la materia. Véase: Amunátegui y Solar, Domingo, Los primeros años del Instituto Nacional (1813-1835), Impr. Cervantes, Santiago, 1889, p. 563.

47 Se llamó Principios de Derecho de Gentes cuando fue publicado por primera vez en 1832, pero siguiendo la terminología de Bentham, el nombre fue cambiado a Principios de Derecho Internacional en la tercera edición de 1864. Vid: Lagos Carmona, Guillermo, Andrés Bello, El maestro del Derecho Internacional, Andrés Bello, Santiago, 1982, pp. 33-36.

${ }^{48}$ Cuando el Código Civil finalmente entró en vigencia en 1856 hubo mucho debate acerca de si debía igualmente enseñarse el viejo Derecho castellano. Finalmente, en 1857, se decidió que debía abolirse el estudio del Derecho español y se creó la asignatura de Derecho Civil. Significativamente la signatura no se llamó Código Civil. Vid: Guzmán Brito, Alejandro, "Los dos primeros libros chilenos de derecho civil patrio”, en Revista de Estudios Histórico-Jurídicos 11 (1986), p. 148.

${ }^{49}$ Esta modificación se introdujo en 1850. Vid: Baeza Marambio, Mario, Esquema y notas para una Historia de la Facultad de Ciencias Jurídicas y Sociales de la Universidad de Chile, Santiago, 1944, p. 137.

${ }^{50}$ Originalmente, para ejercer esta facultad era menester haber aprobado Derecho romano y Derecho natural, pero estos requisitos fueron sucesivamente relajados en 1876 y 1878 . Esta facultad fue solo abolida en 1917 . 
Durante este período, el Derecho se estudiaba de una forma crecientemente exegética. Mientras se codificaba el Derecho, las materias codificadas pasaron a estudiarse en el orden entregado por los códigos, ocasionalmente agregando algunos comentarios relativos a las disposiciones de los mismos. Fue significativo el cambio de nombre que experimentó la asignatura de Derecho Civil, que pasó a llamarse Código Civil luego de la reforma de 1863, solo unos pocos años después de la promulgación del Código. De hecho, en las siguientes reformas, la inclusión de nuevas materias siguió de cerca la promulgación de nuevos códigos. Este estilo, que se llamó reexposición literal ${ }^{51}$, fue asociado a la École du Exégèses, no obstante carecer del marco filosófico de la famosa escuela francesa. Esta forma de enseñar parecía ser una respuesta relativamente simplista al conocimiento jurídico bastante básico que existía en Chile por entonces. De hecho, durante la Colonia una de las pocas cosas que los estudiantes de Derecho conocían bien eran las Instituciones de Justiniano, casi de memoria y con pocos comentarios, por la carencia de libros impresos. Este mismo tipo de aprendizaje memorístico parece persistir en el corazón de la universidad chilena del siglo XIX, no tanto por una posición filosófica acerca de la naturaleza del Derecho, sino simplemente por la incapacidad de hacer algo más profundo. De hecho, no hubo ningún quiebre con el Derecho tradicional español, y las Siete Partidas eran aún conocidas y citadas a lo largo de todo el siglo $\mathrm{XIX}^{52}$.

Aunque la investigación jurídica y la producción académica eran más bien escasas, es notable que poco después de la Independencia las primeras obras jurídicas aparecie$\operatorname{sen}^{53}$. Una de ellas es una suerte de concordancia entre el Código Civil, sus proyectos y algunos códigos extranjeros ${ }^{54}$, otra es un diccionario del Código Civil ${ }^{55}$. Estos fueron, de hecho, ejercicios comparativos, ya que tenían en cuenta tanto al Code Napoléon como al Derecho tradicional español. Las dos primeras exposiciones completas del Código Civil fueron publicadas poco después de su promulgación, en $1863^{56}$. Estas fueron obras bastante básicas y apuntaban simplemente a explicar las disposiciones del Código Civil siguiendo su orden y sistemática. Estas fueron seguidas por estudios de mayor

${ }^{51}$ Guzmán Brito, Alejandro, "El Código Civil de Chile y sus primeros intérpretes”, en Revista Chilena de Derecho 19-1 (1992), p. 86

52 Vid: Guzmán Brito, Alejandro, "El Código Civil de Chile y sus primeros intérpretes”, en Revista Chilena de Derecho 19-1 (1992), pp. 81-88.

53 El primer trabajo jurídico publicado en Chile fue básicamente una reedición de un manual de testamentos publicado en Filipinas por Pedro Mujillo Valverde. En cualquier caso, desde 1843 el anuario Anales de la Universidad de Chile publicó regularmente trabajos jurídicos, algunos de los cuales eran los resultados de investigaciones realizadas por los propios estudiantes de Derecho, a fin de obtener su grado de licenciado. Leyéndolas uno puede hacerse una idea bastante completa de la cultura jurídica que existía en el siglo XIX en Chile.

${ }^{54}$ Por ejemplo, López, Vitalicio A., Razón i Fuente de la lei o Concordancia del Código Civil con el proyecto de que se formó, Ferrocarril, Santiago, 1858.

55 González, Florentino, Diccionario de Derecho Civil Chileno o Exposición por orden alfabético de las disposiciones del derecho civil de Chile y de aquellas leyes que es importante conocer, El Comercio, Valparaíso,1862.

56 Estas son Lastarria, José Victorino, Institutos de Derecho Civil Chileno, El Comercio, Lima, 1863 y Fabres, José Clemente, Instituciones de Derecho Civil Chileno, El Universo, Valparaíso, 1863. 
profundidad conocidos como comentarios, que apuntaban a un fin más ambicioso, como era el explicar las disposiciones del Código Civil a la luz de la jurisprudencia y realizar ejercicios comparativos con el Derecho francés y el español ${ }^{57}$. Durante el período final del siglo XIX apareció la primera revista jurídica chilena, la Revista Forense Chilena, que fue publicada regularmente entre 1885 y 1892. Aunque no permaneció como órgano de difusión y presentación de investigaciones jurídicas, pronto, a comienzos del siglo XX, las revistas jurídicas se convirtieron en un instrumento importante para la presentación de investigaciones jurídicas a una comunidad más amplia.

No obstante, hacia mediados del siglo XIX el cariz restringido de la enseñanza del Derecho se convirtió en un tema de debate. Fernández Concha, en su discurso de incorporación como profesor de la Universidad de Chile en 1857, critica agudamente la falta de una perspectiva filosófica en la docencia jurídica y su enfoque restringidamente legalista ${ }^{58}$. Aunque el autor, desde su posición conservadora, no aborda los problemas más profundos de los estudios exegéticos y su profunda dependencia de la legislación para el análisis dogmático, él apunta a un problema importante cuando reclama una perspectiva más amplia para los estudios jurídicos.

Durante la parte final del siglo XIX había una tendencia a abandonar la perspectiva marcadamente legalista que habían adquirido los estudios jurídicos. Domeyko señala que en 1880 las clases ya no eran una repetición textual de las disposiciones legales, sino que los profesores comenzaron a innovar en sus perspectivas jurídicas ${ }^{59}$. Esto traerá cambios de gran importancia para la educación jurídica a comienzos del siglo XX.

\section{IV. ¿UNA OPORTUNIDAD PERDIDA?}

A fines del siglo XIX la educación jurídica había alcanzado una etapa madura y su antigua estructura no era capaz de expresar el conocimiento jurídico acumulado a lo largo del siglo. El viejo método exegético ya no parecía capaz de mostrar las complejidades que la interpretación de los códigos había adquirido. En este contexto, la influencia de la doctrina francesa de fines del siglo XIX y comienzos del XX resultó fundamental para la renovación del Derecho privado. El pandectismo penetró en las universidades chilenas no mediante los autores alemanes, que permanecieron principalmente desconocidos hasta mucho más adelante, sino gracias a la obra de Charles Aubry

${ }^{57}$ El primero está, desafortunadamente, incompleto. Es Chacón, Jacinto, Exposición razonada y estudio comparativo del Código Civil Chileno, El Mercurio, Valparaíso, 1868. Fue sucedido por otro estudio incompleto: Alfonso, Paulino, Explicaciones del Código Civil, Cervantes, Santiago, 1882. Aunque hubo otros intentos de intención más limitada, el primer comentario completo del Código Civil es: Vera, Robustiano, Comentario del Código Civil, Gutenberg, Santiago, 1894, en siete volúmenes.

58 Vid: Fernández Concha, Rafael, "Discurso de Incorporación”, en Anales de la Universidad de Chile, 15-1 (1857), pp. 131-142.

${ }^{59}$ Esta observación está incluida en un informe de 1880 realizado por Ignacio Domeyko. Vid: Anales de la Universidad de Chile (1881), 60 p. 209. 
y Frédéric Charles Rau, Course de Droit Civil Français. Como es bien sabido, esta es una adaptación del trabajo de Karl Salomo Zachariä, Handbuch des französischen Civilrechts, que explicaba el Derecho francés a la luz del pandectismo alemán. Siguiendo su ejemplo y métodos, Luis Claro Solar escribió el primer comentario sistemático del Código Civil en su monumental Explicaciones de Derecho Civil Chileno y Comparado (1898-1927). Estos comentarios permanecen como el más completo análisis del Código Civil chileno. Como su título sugiere, contienen una aproximación comparativa, principalmente, más no exclusivamente, considerando en ella al BGB y el Código Napoleón, como también la doctrina francesa de su tiempo (con especial énfasis en Planiol, Josserand y Ripert). Tomó también en consideración el Derecho tradicional español que forma la base del Código Civil, considerando las Siete Partidas y la doctrina de comienzos del siglo XIX, como fuentes del Código Civil, como también el Derecho Romano. En sí mismo, es un esfuerzo histórico-comparativo notable, que fue inmediatamente adoptado por el foro y que ha tenido una enorme influencia en los estudios jurídicos.

La educación fue puesta a debate en este mismo período. Una proposición para renovarla fue levantada en $1901^{60}$, que incluía el abandono del método exegético, a fin de abrazar una perspectiva sistemática, siguiendo el modelo pandectista ${ }^{61}$. En 1902, el Consejo Universitario aprobó el plan. El nombre de la principal asignatura de Derecho privado, Código Civil, fue cambiado a Derecho Civil, a fin de hacer explícito el cambio metodológico ${ }^{62}$. Un elemento importante del cambio metodológico fue la inclusión de elementos comparativos dentro del currículo. En efecto, el nuevo plan incluía una asignatura de Derecho comparado como optativa en el último año, iniciando, de esta manera, el estudio formal del mismo en nuestra tradición universitaria. Por influencia de

${ }^{60}$ Este fue propuesto por Alejandro Álvarez (Vid: Álvarez, Alejandro, La nueva tendencia en el estudio del derecho civil: según la pedagogía moderna y según el resultado de las ciencias políticas y sociales, Imprenta Moderna, Santiago, 1900). Su plan era, básicamente, reemplazar el estudio exegético por la exposición sistemática del Derecho privado, a fin de elaborar construcciones jurídicas. Esta idea, que está tomada en último término del pandectismo, parece, en su caso, consecuencia de la jurisprudencia francesa de fines del XIX. Para más detalles véase: Baeza Marambio, Mario, Esquema y notas para una Historia de la Facultad de Ciencias Jurídicas y Sociales de la Universidad de Chile, Santiago, 1944, p. 195.

${ }^{61} \mathrm{La}$ influencia del pandectismo, que era llamado constructivismo en Chile, puede ser comprobada por los comentarios realizados al programa de enseñanza jurídica por Tomás A. Ramírez, quien consideraba que esta era la única forma válida de interpretar las disposiciones jurídicas. En su exposición (Sesión de 22 de abril de 1907 del Consejo de Instrucción Pública en Anales de la Universidad de Chile, 1907, p. 67) él dice expresamente que el método está tomado de Zachariä por medio de Aubry y Rau. Para más detalles, véase: Valdivieso Lobos, Leonardo Enrique, Historia de la cátedra de Derecho civil en la Universidad de Chile, Memoria para optar al grado de licenciado, Santiago, 2005, p. 67.

${ }^{62} \mathrm{El}$ rector de la Universidad en su informe sobre el estado de la Universidad dice expresamente que:

"Como lo indica el nombre de los ramos establecidos en el nuevo plan de estudios, al comentario del Código se ha sustituido la enseñanza del derecho correspondiente, dando así mayor generalidad a esta enseñanza y elevándola por encima de nuestra propia legislación, la cual no debe presentarse al criterio del alumno como única e inconmovible base de sus conocimientos jurídicos, sino como la expresión de ideas más fundamentales y sintéticas, aplicadas a un estado social determinado”. Barros Borgoño, Manuel, "Memoria del Rector de la Universidad Correspondiente al año 1901", en Anales de la Universidad de Chile 110 (1902), p. 123. 
Valentín Letelier, Historia del Derecho reemplazó al viejo Derecho Canónico, que había perdido su sentido original en un país crecientemente secularizado. El viejo manual de Bello de Derecho Romano fue reemplazado por literatura más al día. La reforma completa puede ser resumida -como de hecho lo fue algunos años después ${ }^{63}$ - en el lema "más allá de los códigos".

Durante los años que siguieron, la reforma fue aplicada y dio a Chile un panorama jurídico cada vez más complejo. La literatura jurídica floreció y ganó consistencia ${ }^{64}$, mientras que las universidades se expandieron ${ }^{65}$. No obstante, la Universidad de entonces tenía un defecto fatal que pondría un techo al desarrollo de la cultura jurídica chilena: no se dio ninguna importancia a la formación de juristas de nivel superior que pudiesen desarrollar la investigación jurídica. De hecho, debe recordarse que no había formación doctoral en Chile desde la Independencia. Así, los académicos eran simplemente abogados importantes que pasaban parte de su tiempo libre enseñando Derecho. No había profesores, al menos de la forma en que se los comprende en la mayor parte de los países de tradición continental, ni podía haber ningún tipo de debate académico vívido en materias jurídicas. Esta falta de espacio intelectual para el desarrollo jurídico era profundamente sentida entre los estudiantes ${ }^{66}$ y uno de los principales puntos del siguiente período de reformas tuvo por finalidad el establecer un ambiente académico propiamente tal para el mundo jurídico. Las ideas propuestas para superar esta dificultad fueron enviar estudiantes al extranjero a fin de profundizar sus estudios jurídicos y abrir en Chile un programa de doctorado ${ }^{67}$.

En la década de 1920 una nueva reforma fue propuesta. Esta incluía algunas reformas menores en el programa de pregrado, pero su centro era la proposición de crear un programa de doctorado en Derecho ${ }^{68}$, como también el enviar de forma sistemática a

${ }^{63}$ Vid: Iribarren, Juan Antonio, "Los Estudios Jurídico-Sociales", en Anales de la Universidad de Chile 72, t. 134 (1914), pp. 421-542.

${ }^{64}$ La Revista de Derecho y Jurisprudencia, fundada en 1904, estaba destinada a ser la expresión de estas nuevas tendencias. Aunque finalmente desapareció en 1988, ella creó nuevos estándares para la investigación jurídica.

${ }^{65}$ A la Universidad de Chile, la Pontificia Universidad Católica de Chile y la Pontificia Universidad Católica de Valparaíso, se agregó la Universidad de Concepción en 1928.

${ }^{66} \mathrm{El}$ análisis más convincente en este sentido lo hace ya Iribarren, quien clamaba por la creación de un profesorado que tuviese los estándares de Alemania. Él también propuso la creación de un programa de doctorado que se enfocase en el Derecho comparado y la Historia del Derecho. Vid: Iribarren, Juan Antonio, "Los Estudios Jurídico-Sociales", en Anales de la Universidad de Chile 72, t. 134 (1914), pp. 421-542.

${ }^{67}$ Ambos aparecen por primera vez en el trabajo de Iribarren (Vid: Iribarren, Juan Antonio, "Los Estudios Jurídico-Sociales”, en Anales de la Universidad de Chile 72, t. 134 (1914), pp. 421-542), pero son insistentemente repetidos en varias oportunidades en los años cuarenta (Baeza Marambio, Mario, Esquema y notas para una Historia de la Facultad de Ciencias Jurídicas y Sociales de la Universidad de Chile, Santiago, 1944, p. 206) y sesenta (Bascuñán Valdés, Aníbal, Pedagogía Jurídica, Editorial Jurídica, Santiago, 1954 , pp. 112-113).

${ }^{68} \mathrm{La}$ idea fue acariciada durante las primeras décadas del siglo XX. Fue propuesta como una forma de mejorar la calidad de la academia en 1914 (Vid: Iribarren, Juan Antonio, "Los Estudios Jurídico-Sociales", en Anales de la Universidad de Chile 72, t. 134 (1914), pp. 421-542) e incluso un programa de doctorado fue aprobado por la Pontificia Universidad Católica de Chile en 1915, aunque nunca se lo implementó. Lo 
estudiantes destacados al extranjero. Finalmente, en $1927^{69}$ se establecieron por ley las bases para abrir programas de doctorado en Chile. No obstante, ningún programa de doctorado en Derecho se abriría en Chile por los próximos setenta años.

Los estudiosos del Derecho no han investigado las razones de este fracaso. Permanece como un hecho en bruto de la Historia jurídica chilena, que se vuelve aún más misterioso si se recuerda que fue repetidamente propuesta en los cuarenta y sesenta del pasado siglo. De hecho, la falta de un ambiente académico propicio para la investigación jurídica se dejó sentir durante los noventa e incluso a comienzos de la primera década del nuevo siglo ${ }^{70}$.

Desde nuestro punto de vista, el fracaso inicial en abrir un espacio propiamente académico para el estudio del Derecho en Chile en la década del veinte y treinta se debe al enorme impacto de la Gran Depresión en la vida económica chilena. En efecto, Chile fue el país más profundamente afectado del mundo por la Depresión de 1930 y sus efectos eran visibles varias décadas después. Esto trajo inestabilidad política a Chile, donde una sucesión de gobiernos inestables se sucedieron durante los años treinta, incluyendo golpes de Estado y una efímera república socialista. De hecho, esta inestabilidad política puede ser percibida en los cambiantes programas de currículo que fueron aprobados durante la época ${ }^{71}$. La inestabilidad política no es compatible con la actividad académica y no existió un ambiente social pacífico en Chile hasta fines de la década del treinta, cuando los gobiernos elegidos democráticamente se volvieron a transformar en regla.

Sin embargo, hubo un segundo fracaso en la educación en general durante esta época. Chile no fue capaz de convertirse en una sociedad abierta y materias que eran hasta entonces privilegios de una élite, no fueron transformados en derechos sociales ${ }^{72}$. Entre 1907 y 1970 la población total pasó de casi tres millones de habitantes a nueve, con un creciente nivel de urbanización y niveles educativos más altos, desde que la primaria se hizo obligatoria en 1920. No obstante, el número de facultades de derecho permaneció constante, en las mismas cuatro que existían en 1928. Es decir, mientras la población aumentaba y la educación básica también, la universidad se mantenía como un asunto primariamente concerniente a la élite. De hecho, la tendencia en contra de la masificación de los estudios superiores se mantuvo hasta fines del siglo.

Por otra parte, la atmósfera política estaba dominada por las necesidades económicas inmediatas. La pobreza rampante hacía que los éxitos de los gobiernos se midiesen en

mismo sucedió con el programa doctoral aprobado por la Universidad de Chile en 1924 (vid: Guzmán Brito, Alejandro, "La enseñanza de Derecho en Chile. Historia y perspectivas", en Anales del Instituto de Chile 25 (2005-6), pp. 306-307).

${ }^{69}$ Es el Decreto con Fuerza de Ley 7500.

${ }^{70}$ Vid: De la Maza G., Íñigo, Los abogados en Chile: desde el Estado al Mercado, s/e, 2001, p. 17; Barahona González, Jorge, "La cultura jurídica chilena: apuntes históricos, tendencias y desafíos”, en Revista de Derecho (Valparaíso) 35-2 (2010), p. 440.

${ }^{71}$ El currículo fue modificado en 1924, 1926, dos veces en 1928, 1930, de nuevo dos veces en 1933 y finalmente en 1934. Esto significa ocho currículos distintos en diez años.

${ }^{72}$ En cuanto a la conversión de privilegios en derechos y su importancia para la transformación de sociedades básicas a abiertas, véase North, Douglass C., Wallis, John Joseph y Weingast, Barry, Violence and Social Orders. A conceptual framework for interpreting recorded human history, Cambridge University Press, Cambridge, 2009, p. 27. 
términos económicos. En un ambiente de pobreza devastadora y elitismo en la educación superior, no resulta extraño que durante los años cincuenta y sesenta la educación en Chile se convirtiese en un campo de batalla para las ideologías. La profundización de la investigación jurídica tenía un lugar muy secundario ${ }^{73}$-cuando no inexistente- en la agenda política de las universidades y del gobierno ${ }^{74}$.

En este contexto, algunos intentos de reforma se llevaron adelante durante los sesenta, a fin de ampliar el currículo de Derecho e incorporar a otras ramas de las ciencias sociales en la formación profesional ${ }^{75}$. En cualquier caso, estos intentos fueron finalmente segados por el golpe militar de 1973, que terminó con cualquier intento de reforma durante los años venideros.

\section{Un RENACIMIENTO}

Cuando comencé a estudiar Derecho a comienzos de la década del noventa, luego de la transición a la democracia, como ya he señalado, la atmósfera jurídica estaba dominada por una estrecha visión positivista (o más bien del positivismo), que mantenía una fe ingenua en la supremacía de la ley como fuente del Derecho. La mayor parte de los profesores eran abogados famosos que hacían de académicos a tiempo parcial. Ninguno tenía tiempo para hacer investigación seria y muchos carecían de las habilidades para dedicarse a ello. Un doctor era una rara avis, hasta el punto que solo puedo recordar a un profesor que me hubiese impartido clases y que tuviese tan inusitado título. Algo impactante de aquel período fue el continuo incremento de facultades de Derecho y de estudiantes en el país.

En 1981 el gobierno había aprobado una nueva regulación para las universidades de Chile ${ }^{76}$. Esta regulación permitía la creación de nuevas universidades privadas, junto a las antiguas universidades creadas antes de la ley, que ahora se denominan tradicionales. Durante los años ochenta y noventa, los números se incrementaron de cuatro a casi treinta facultades de Derecho en el país. Por tanto, unos pocos miles de alumnos se convirtieron en veinticuatro mil súbitamente. La mayor parte de estas facultades eran el resultado de iniciativas precarias, donde poca o ninguna investigación podía tener lugar.

${ }^{73}$ Una honrosa excepción debe mencionarse en relación con el programa Chile-Standford que pretendió incrementar la investigación en lo relativo al Derecho y el desarrollo. Vid: Merryman, John Henry, "Law and Development Memoires: The Chile Law Program”, en The American Journal of Comparative Law 48-3 (2000), pp. 481-499

${ }^{74}$ De hecho, los especialistas en Derecho perdieron su predominancia política durante el período. Vid: Bravo Lira, Bernardino, "Estudios de Derecho y Cultura de abogados en Chile 1758-1998: tras la huella ius commune, codificación y descodificación en el nuevo mundo", en REHJ 20 (1998), pp. 85-106; De la Maza G., Íñigo, Los abogados en Chile: desde el Estado al Mercado, s/e, 2001, pp. 5-17.

${ }^{75}$ Esto fue realizado disminuyendo la importancia de las aproximaciones dogmáticas tradicionales en la formación jurídica e introduciendo perspectivas sociales y económicas al currículo. Su mayor logro fue la reforma de 1966. Vid: Valdivieso Lobos, Leonardo Enrique, Historia de la cátedra de Derecho civil en la Universidad de Chile, Memoria para optar al grado de licenciado, Santiago, 2005, p. 96.

${ }^{76}$ Este fue el Decreto con Fuerza de Ley $\mathrm{N}^{\circ} 1$. 
En este contexto, algunos profesionales del Derecho se dieron cuenta de que podían ganarse la vida trabajando profesionalmente en las universidades. Muchos solían enseñar en dos o tres de ellas -los llamados profesores taxi-, ya que la demanda de profesores era mucho mayor que la oferta. Para fines de los noventa se convirtió en un lugar común para algunos estudiantes el viajar al extranjero a fin de estudiar un doctorado. Algunos fueron dotados de becas por sus propias universidades, que esperaban poder re-contratarlos al finalizar sus estudios. Otros simplemente solicitaron préstamos bancarios a fin de pagar la aventura. Al regresar a Chile, estos recién doctorados se convirtieron en el corazón de la investigación jurídica en las nuevas facultades de Derecho.

Para fines de la década del noventa, la percepción de encontrarse la educación jurídica en crisis era un lugar común. Las reformas fueron promovidas desde dos polos, desde el mercado y desde el Estado. Por un lado se desarrolló un mercado universitario segmentado ${ }^{77}$. Las universidades se dividieron entre aquellas orientadas a la élite y aquellas que no lo estaban. Las que se orientaron hacia la élite tenían mayor número de profesores de jornada, con mejores calificaciones académicas y perfiles más destacados, lo que les permitió atraer más y mejores estudiantes y aumentar sus valores de matrícula. Para cualquier facultad de Derecho se hizo atractivo en un mercado educacional competitivo; se hicieron necesarias altas inversiones en capital humano y toda clase de mecanismos de mercado fueron implementados para atraer nuevos talentos a su equipo. En pocos años, las facultades de Derecho más prestigiosas pasaron de tener muy pocos profesores de jornada completa con grado de doctor, a estar mayoritariamente compuestas por ellos ${ }^{78}$. Se abrieron programas de doctorado ${ }^{79}$ y las revistas jurídicas florecieron ${ }^{80}$.

Por parte del Estado se intervino de dos maneras, por un lado se pusieron incentivos económicos a favor de los académicos y de las instituciones a fin de promover la investigación ${ }^{81}$, y mediante la creación de un programa de acreditación ${ }^{82}$ que da acceso a fondos públicos a aquellas instituciones que se sometiesen a él. Aunque pueden esperarse

77 Vid: Salas Opazo, Víctor, “Segmentación en el 'mercado' del pregrado universitario chileno", en ENEFA Proceedings 5 (2012), pp. 2708-2727

${ }^{78}$ Por ejemplo, mi propia facultad tenía a comienzos del 2000 solo seis profesores de jornada completa con el grado de doctor. Diez años más tarde, tenía veinticinco. El número sigue incrementándose y probablemente llegue a cuarenta a fines de la década. Recientemente fui informado de planes para aumentar el número de profesores con grado de doctor en la Universidad de Chile a la mastodóntica cantidad de 108 para fines de esta década, aunque aún hay demasiadas incertidumbres al respecto.

${ }^{79}$ El mismo Decreto con Fuerza de Ley N ${ }^{\circ} 1$ de 1981 regulaba la consecución del grado de doctor. En cualquier caso, el primer programa doctoral no se abrió hasta 2001. Hoy hay siete programas doctorales en Derecho en Chile, los que experimentan un rápido desarrollo.

${ }^{80}$ Hay aproximadamente treinta revistas científicas en Derecho, de ellas ocho están incluidas en índices internacionales relevantes.

${ }^{81}$ Un buen número de fondos concursables fueron creados fundamentalmente por CONICYT. Estos benefician a investigadores que, a base de un concurso competitivo, reciben financiamiento público para sus investigaciones, $\mathrm{y}$ a instituciones universitarias al mejorar sus oportunidades para obtener financiamiento público.

${ }^{82}$ Esto fue creado por la Ley $\mathrm{N}^{\circ} 20.129$ de 2006. 
reformas mayores en este último ${ }^{83}$, el continuo incremento en la investigación jurídica probablemente continuará.

Este auge de la investigación jurídica es uno de los eventos más importantes en la Historia jurídica chilena. Por primera vez en su Historia, el Derecho en Chile ha adquirido una perspectiva científica seria. Esto influenciará los futuros desarrollos jurídicos de formas impredecibles y, ojalá, positivas.

\section{BiBLIOGRAFÍA}

Aedo Barrena, Cristián, "El concepto normativo de la culpa como criterio de distribución de riesgos. Un análisis jurisprudencial”, en Revista Chilena de Derecho 41-2 (2014), pp. 705-728

Alfonso, Paulino, Explicaciones del Código Civil, Cervantes, Santiago, 1882.

Álvarez, Alejandro, La nueva tendencia en el estudio del derecho civil: según la pedagogía moderna y según el resultado de las ciencias políticas y sociales, Imprenta Moderna, Santiago, 1900.

Amunátegui, Miguel Luis, "La Universidad de San Felipe", en Anales de la Universidad de Chile (1874).

Amunátegui y Solar, Domingo, Los primeros años del Instituto Nacional (1813-1835), Impr. Cervantes, Santiago, 1889.

Amunátegui Perelló, Carlos Felipe, Derecho Civil y Medioambiente, Thomson Reuters Santiago, 2014.

Baeza Marambio, Mario, Esquema y notas para una Historia de la Facultad de Ciencias Jurídicas y Sociales de la Universidad de Chile, Santiago, 1944.

Barahona González, Jorge, "La cultura jurídica chilena: apuntes históricos, tendencias y desafíos”, en Revista de Derecho (Valparaíso) 35-2 (2010).

Barros Borgoño, Manuel, "Memoria del Rector de la Universidad Correspondiente al año 1901", en Anales de la Universidad de Chile 110 (1902).

Bascuñán Valdés, Aníbal, Pedagogía Jurídica, Editorial Jurídica, Santiago, 1954.

Bravo Lira, Bernardino, "Estudios de Derecho y Cultura de abogados en Chile 1758-1998: tras la huella ius commune, codificación y descodificación en el nuevo mundo", en REHJ 20 (1998), pp. 85-106.

Chacón, Jacinto, Exposición razonada y estudio comparativo del Código Civil Chileno, El Mercurio, Valparaíso, 1868.

Colección de Documentos Inéditos Relativos al Descubrimiento, Conquista y Organización de las Antiguas Posesiones Españolas de Ultramar, Real Academia de la Historia, Madrid, 1890, t. 5 .

De la Maza, G., Íñigo, Los abogados en Chile: desde el Estado al Mercado, s/e, 2001.

Fabres, José Clemente, Instituciones de Derecho Civil Chileno, El Universo, Valparaíso, 1863.

Fernández Concha, Rafael, "Discurso de Incorporación", en Anales de la Universidad de Chile, 15-1 (1857).

\footnotetext{
${ }^{83}$ Hoy el sistema educativo chileno está bajo discusión. Es sumamente probable que nuevas reformas se implementen durante el gobierno de Bachelet, las que probablemente lleven a que el Estado asuma los costes de matrícula en las universidades que se encuentren acreditadas, sean públicas o privadas. Si las decisiones correctas son tomadas, esto podría llevar a un acceso más igualitario a la educación superior y, ojalá, también a una mejora general en la calidad del sistema.
} 
Fuenzalida Grandón, Alejandro, Historia del desarrollo intelectual en Chile, Imprenta Universitaria, Santiago, 1903.

GonzÁLEz Echeñique, Javier, Los Estudios Jurídicos y la Abogacía en el Reino de Chile, Tesis para el Grado de Licenciado, Universidad Católica de Chile, Facultad de Ciencias Jurídicas, Políticas y Sociales.

GonzÁlez, Florentino, Diccionario de Derecho Civil Chileno o Exposición por orden alfabético de las disposiciones del derecho civil de Chile y de aquellas leyes que es importante conocer, El Comercio, Valparaiso, 1862.

GonzÁlez Morales, Felipe, "Cultura Judicial y Enseñanza del Derecho en Chile: una aproximación", en Colección de Informes de Investigación 14-5 (2003).

GuZMÁn Brito, Alejandro, "Los dos primeros libros chilenos de derecho civil patrio", en Revista de Estudios Histórico-Jurídicos 11 (1986).

Guzmán Brito, Alejandro, "El Código Civil de Chile y sus primeros interpretes”, en Revista Chilena de Derecho 19-1 (1992).

GuZMán Brito, Alejandro, "La enseñanza de Derecho en Chile. Historia y perspectivas", en Anales del Instituto de Chile 25 (2005-6).

Hanisch Espíndola, Hugo, Andrés Bello y su obra en Derecho Romano, Consejo de Rectores de las Universidades Chilenas, Santiago, 1983.

Iribarren, Juan Antonio, "Los Estudios Jurídico-Sociales", en Anales de la Universidad de Chile 72, t. 134 (1914).

Lagos Carmona, Guillermo, Andrés Bello, El maestro del Derecho Internacional, Andrés Bello, Santiago, 1982.

Lastarria, José Victorino, Institutos de Derecho Civil Chileno, El Comercio, Lima, 1863.

López, Vitalicio A., Razón i Fuente de la lei o Concordancia del Código Civil con el proyecto de que se formó, Ferrocarril, Santiago, 1858.

Medina, José Toribio, La instrucción pública en Chile, imprenta Elzeviriana, Santiago, 1905.

Medina, José Toribio, Historia de la Real Universidad de San Felipe de Santiago de Chile, Universo, Santiago, 1928, t. I.

Merryman, John Henry, "Law and Development Memoires: The Chile Law Program", en The American Journal of Comparative Law 48-3 (2000), pp. 481-499.

North, Douglass C., Wallis, John Joseph y Weingast, Barry, Violence and Social Orders. A conceptual framework for interpreting recorded human history, Cambridge University Press, Cambridge, 2009.

Recopilación de Leyes de Indias, Bartholome Ulloa, Madrid, 1774.

Rutherford Parentti, Romy Grace, "La reparación del daño moral derivado del incumplimiento contractual: tendencia en la reciente jurisprudencia nacional y española”, en Revista Chilena de Derecho 40-2 (2013), pp. 669-689.

Salas Opazo, Víctor, "Segmentación en el 'mercado' del pregrado universitario chileno", en ENEFA Proceedings 5 (2012).

SAN Martín Neira, Lilian C., "Responsabilidad precontractual por ruptura injustificada de negociaciones", Revista Chilena de Derecho, 40-1 (2013), 317-324.

Sesiones de los Cuerpos Lejislativos de la República de Chile. 1811 a 1845, Santiago, Cervantes, 1887, t. 1.

Serrano, Sol, Ponce de León, Macarena y Rengifo, Francisca, Historia de la Educación en Chile, (1810-2010), Taurus, Santiago, 2012, t. I.

Valdivieso Lobos, Leonardo Enrique, Historia de la cátedra de Derecho civil en la Universidad de Chile, Memoria para optar al grado de licenciado, Santiago, 2005.

Vera, Robustiano, Comentario del Código Civil, Gutenberg, Santiago, 1894. 